\title{
Integrated simulation of the dualistic water cycle and its associated processes in the Haihe River Basin
}

\author{
WANG Hao, JIA YangWen, YANG GuiYu*, ZHOU ZuHao, QIU YaQin, NIU CunWen \& \\ PENG Hui
}

State Key Laboratory of Simulation and Regulation of Water Cycle in River Basin, China Institute of Water Resources and Hydropower Research, Beijing 100038, China

Received May 6, 2012; accepted October 25, 2012; published online March 1, 2013

\begin{abstract}
Water resource shortages, water environmental deterioration, and water ecological degradation are becoming increasingly prominent in the Haihe River Basin under the effects of global climate change and intense human activity. Finding ways to solve these problems reasonably is an urgent task in basin water resources management. The water cycle describes the formation and transformation of every water drop, while it interacts with associated water ecology and water environment processes. Therefore, to fundamentally solve the above problems, the three processes must be combined and the evolutionary trends of the ecology and water environment driven by the water cycle must be determined. To comprehensively diagnose and solve the problems of water resources, ecology and water environment in the basin, an integrated simulation platform of the dualistic water cycle and its associated processes in the Haihe River Basin was established by fully analyzing the "natural-social" dualistic characteristics of the evolution of the basin water cycle in this study. Accordingly, it is a supporting tool to evaluate the future trends of water resources, ecology and the water environment by setting scenarios based on the predictions of a climate mode and water control conditions. The results show that with climate change, the water consumption, groundwater overexploitation, and the amount of water flowing to the sea could develop soundly and satisfy the requirements of national economic growth in the future planning year 2030 through the implementation of water consumption control management and the South-North Water Diversion Project. Meanwhile, associated water environmental deterioration can be alleviated, and a growing trend for production capacities of the natural ecosystem and agro-ecosystem is seen. The above results provide a foundation for implementing basin water resources regulation and the most strict water resources management.
\end{abstract}

natural-social dualistic characteristics, evolutionary mechanism, water cycle, water environment, ecology, Haihe River Basin

Citation: Wang H, Jia Y W, Yang G Y, et al. Integrated simulation of the dualistic water cycle and its associated processes in the Haihe River Basin. Chin Sci Bull, 2013, 58: 3297-3311, doi: 10.1007/s11434-012-5371-0

With economic development and population growth, a series of ecological and environmental problems have been triggered by water shortages. In addition, global climate change is leading to greater uncertainty in the future evolution of basin water resources, higher frequency of the occurrence of droughts and floods, and greater vulnerability of water ecology and the water environment. These water-related issues have become the focus of global attention [1-8]. However, the manifestation of any water issue can be

\footnotetext{
*Corresponding author (email: guiyuy@iwhr.com)
}

attributed to the evolution of water-cycle processes, because the water cycle describes the formation and transformation of every water drop and is associated with water ecology, the water environment and any other related processes in a relationship of action and reaction (Figure 1). Therefore, how to rationally use every drop of water, coordinate the interaction among the three systems (i.e., water resources, ecology and the water environment) in the water cycle and maintain a sound water cycle are directly related to basin/regional sustainable development. However, because of intense human activity, the basin water cycle has changed 


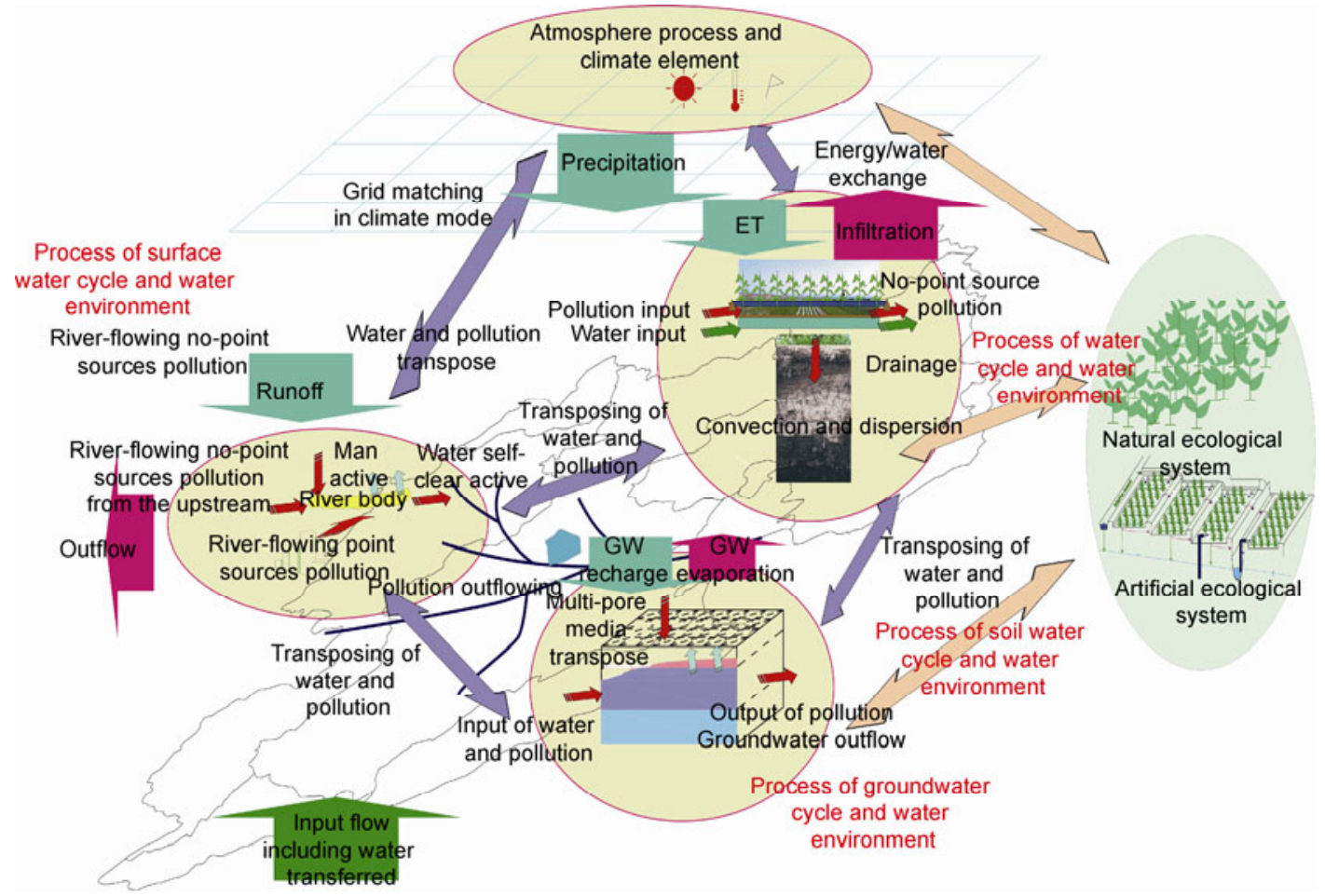

Figure 1 (Color online) Interaction among the water cycle system, water environment system and ecology system.

gradually from the dominant "natural" unitary mode to the "natural-social" (or "natural-artificial") dualistic coupled mode. Thus, faced with increasingly prominent dualistic-water-cycle characteristics, the evolutionary mechanisms of the water cycle, ecology and water environment driven by the water cycle cannot be fully revealed only using the traditional natural unitary-water-cycle mode. A research hotspot is the water cycle and the related field of ecology and the water environment driven by a dualistic-water-cycle mode. For example, the Soil and Water Assessment Tool (SWAT), developed by the Agricultural Research Service, U.S. Department of Agriculture in 1994 [9], successively added agricultural irrigation, urban water usage and other social water-cycle factors, introduced a crop growth model, improved the calculation of the water quality in terms of river nutrients, and simulated pesticide migration during latter development. The improvements of the SWAT model realized the simulation of the dualistic water cycle and its associated ecology and environmental processes to a certain extent. However, the advantages of the model are still focused on the simulation of the natural water cycle. The SWAT model lacks full consideration of the water resource configuration combined with allocation, macro-economy, industrial structure and other social water cycle factors, and thus incompletely simulates the water ecology and water environment associated with the water cycle. The European Hydrological System model (SHE) [10] has the same functionality as the SWAT model; i.e., the model reflects factors of the social water cycle and characteristics of the water environment in the natural water cycle by changing the land-use condition and embedding a water environment module. However, the core object of the SHE model is still the natural water cycle without further simulation of processes of the social water cycle and ecology. The Water Evaluation and Planning System (WEAP) model [11] developed in Sweden has a strong function of simulating the social water cycle. However, since the WEAP model does not simulate the natural water cycle, ecological processes and environmental processes, it cannot be used to comprehensively study the dualistic water cycle and its associated processes. In addition, although some researchers have carried out more comprehensive analyses of the dualistic characteristics of the water cycle [12] using statistical data, their studies have not systematically resolved the physical mechanism for the water cycle interior, and its associated processes in the water environment and ecology system. In short, systematic studies on the natural-social dualistic water cycle and its associated processes have rarely been reported.

Under the effects of intense human activity and global climate change, the water cycle in the Haihe River Basin has distinct natural-social dualistic characteristics. Specifically, the natural water cycle flux has reduced in terms of basin runoff generation, river runoff, and water flowing to the sea, while the social water cycle flux has tended to increase in terms of water supply, usage, consumption, and discharge. Coupled with the relatively poor conditions of water resources in the basin, the issues of water shortage, 
water ecology degradation, and water environmental deterioration have become increasingly prominent. To fully diagnose and solve the issues relating to basin water resources, water ecology and the water environment, the present study established an integrated simulation and prediction model platform for the dualistic water cycle and its associated processes in the Haihe River Basin based on comprehensively analyzing the dualistic characteristics of water-cycle evolution in the basin. The platform could be used to simulate and analyze future evolutionary trends of basin water resources, water ecology and the water environment in different scenarios. Related results could provide support for water-cycle regulation and water resources management based on the whole water cycle process in the Haihe River Basin.

\section{Haihe River Basin and the dualistic evolu- tionary mechanism of its water cycle}

\subsection{Haihe River Basin}

The Haihe River Basin is located in eastern China between $112^{\circ} \mathrm{E}-120^{\circ} \mathrm{E}$ and $35^{\circ} \mathrm{N}-43^{\circ} \mathrm{N}$. The basin covers Beijing, Tianjin, Hebei and five other provinces (autonomous regions and municipalities) and has a total area of $320000 \mathrm{~km}^{2}$, accounting for $3.3 \%$ of the national area. The basin is China's political and cultural center and is also an economically developed area. In the basin, the mountain area of 189000 $\mathrm{km}^{2}$ accounts for $59 \%$ of the basin, and the rest $41 \%$ is plains, The total population reached 137 million in 2008, accounting for $10.3 \%$ of the national population; the urbanization rate reached $37.4 \%$, far higher than the national average; and gross domestic product (GDP) reached 258 million Yuan accounting for $13 \%$ of the national GDP. However, there is little optimism for the state of the basin's water resources. Since the water demand of social and economic development has far exceeded the carrying capacity of the basin's water resources, there has been a supply and demand imbalance of basin water resources resulting in a series of water ecology and water environmental issues.

According to statistics for 2005 in the whole basin, the per capita water resources amount of $202 \mathrm{~m}^{3}$ is only $13 \%$ of the national average level, which is lower than the internationally recognized per capita water shortage standard of $1000 \mathrm{~m}^{3}$ and extreme water shortage standard of $500 \mathrm{~m}^{3}$. The $3195 \mathrm{~m}^{3}$ water usage per hectare was only $12 \%$ of the national average level [13]. Because of considerable water usage, annual mean water diversion from the Yellow River was more than $4 \times 10^{9} \mathrm{~m}^{3}$ for the basin, where the development and utilization rate of water resources reached $106 \%$, more than the water availability rate of $63 \%$. Meanwhile, the unreasonable water use of economy occupying ecology and environment leaded to almost zero flow in the main rivers in the basin in every year. Moreover, the total area of Baiyangdian, Qilihai and 10 other major wetlands was only $1 / 6$ of the area in the 1950s [14]. To compensate for the water shortage, the groundwater has been overexploited for a long period, and cumulative overexploitation was more than $1 \times 10^{11} \mathrm{~m}^{3}$ in the basin, accounting for $2 / 3$ of the national total overexploitation amount, which leaded to a concentration and contiguous development trend of groundwater funnel [15]. The amount of water flowing to the sea reduced from $2.07 \times 10^{10} \mathrm{~m}^{3}$ in the $1950 \mathrm{~s}$ to $1.7 \times 10^{9}$ $\mathrm{m}^{3}$ in the early 21 st century (see Figure 2 ). In addition, there is serious water pollution. At present, polluted stretches of rivers have a combined length of $7057.0 \mathrm{~km}$, accounting for $59.8 \%$ of the total evaluated length of rivers in the basin, with seriously polluted stretches accounting for $53.6 \%$ of the evaluated river length [16].

\subsection{Dualistic evolutionary mechanism of the water cycle in the Haihe River Basin}

The Haihe River Basin is located in the temperate semihumid and semi-arid continental monsoon climate zone, is sensitive to climate change. Meanwhile, the basin also is China's political and cultural center, and it lies in the third key zone of the national economic development [17] (http:// house.focus.cn/news/2009-10-04/768374.html). The water cycle in the Haihe River Basin undergoes the dual effects of natural changes and intense human activity, displaying obviously natural-social dualistic characteristics.

In term of natural factors, the external driving conditions of the water cycle in the basin have changed because of global climate change and this has led to a declining trend of precipitation with very uneven spatial and temporal distributions. According to the statistics, the multi-annual average precipitation for the basin was $498.8 \mathrm{~mm}$ in the 26 years of 1980-2005, a reduction of $11.9 \%$ compared with precipitation of $566.5 \mathrm{~mm}$ in the 24 years of 1956-1979. Additionally, water resources and the amounts of surface runoff and the amount of water flowing to the sea reduced greatly, as seen in Figure 2.

In term of social factors, large-scale human activity complicated the social water cycle in terms of the complexity of the water supply, water usage, water consumption, and water discharge, greatly affecting the basin's natural water cycle, which was mainly embodied as changes in the flux, structure and path of the water cycle. The flux of the social water cycle had an overall increasing trend in 1980-2005, and the associated cycle structure changed with the water supply and usage pattern. From the perspective of water supply, there was decreasing surface water and increasing groundwater, diverted water and unconventional water. From the perspective of water usage, there was increasing domestic and industrial water usage and decreasing irrigation water usage. The water supply and usage throughout the basin in different years and their structural changes are shown in Figure 3.

The water cycle may also be directly or indirectly affected 


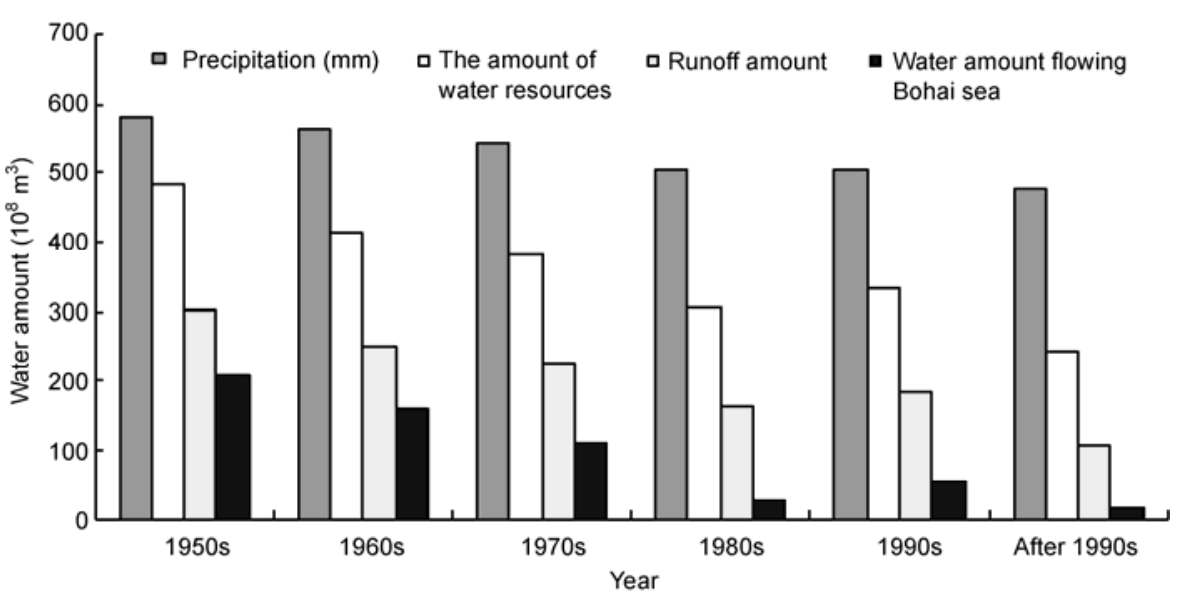

Figure 2 Conditions of water resources in the Haihe River Basin in different years.

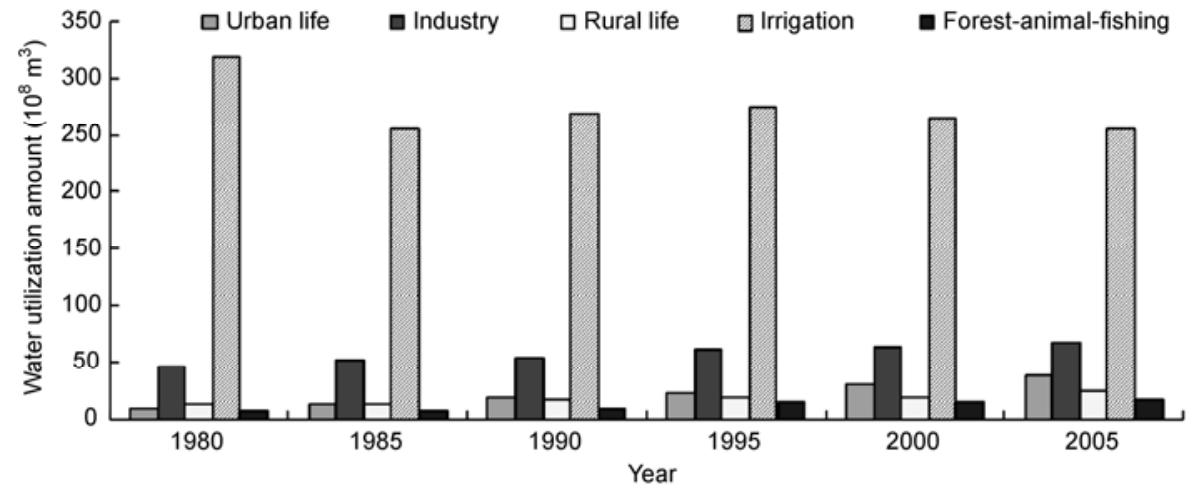

Figure 3 Conditions of water supply and usage in the Haihe River Basin in different years.

by a change in the basin's underlying surface with changes in water conservancy and land use. On the one hand, the construction of water conservancy projects and the subsequent water supply and usage strengthen the transformation link of the natural water cycle flux; on the other hand, changes in the land-use pattern affect the production and consumption of water resources. A total of 34 large reservoirs, 114 medium-sized reservoirs, 1711 small reservoirs and 17505 embankments with water storage capacity had been built in the basin by 2005 . In addition, there are water diversion projects, water lifting projects and the Yellow River Water Diversion Project [18] supplying water for cities in the basin, which directly affect runoff generation and confluence of the natural water cycle. Moreover, with rapidly development of the urbanization and industrialization, the land-use pattern has changed in the basin with the area of arable land declining year by year while the area of urban land increases steadily, which also affects the water cycle path and flux.

In general, under the combined effects of global climate change and human activity, there are profound changes to the driving force, structure and parameters of the water cycle in the basin. The water cycle demonstrates the interdependence of natural and social water cycle systems with reverse change trend. Moreover, under the effects of intense human activity, dualistic evolutionary characteristics are reflected by the continuous growth of the cycle links and paths and ever-changing cycle flux. Accordingly, associated with dualistic water cycle processes, the water environment and ecosystem processes also change in the basin.

\section{Integrated simulation platform of the dualis- tic water cycle and associated processes in the Haihe River Basin}

Because of the complex interaction among the water cycle system, water environment system and ecology system, water is an important driving factor for the latter two systems. To fully reveal the evolutionary characteristics of water resources, the ecology and the water environment, the integrated simulation platform of the dualistic water cycle and its associated processes in the Haihe River Basin was employed. Figure 4 is an overall structural diagram of the integrated simulation platform. In the figure, the NaturalArtificial Dualistic Water Cycle Model (NADUWA) developed with the DAMOS model (a multi-objective decision-making analysis model), ROWAS model (a rule-based 


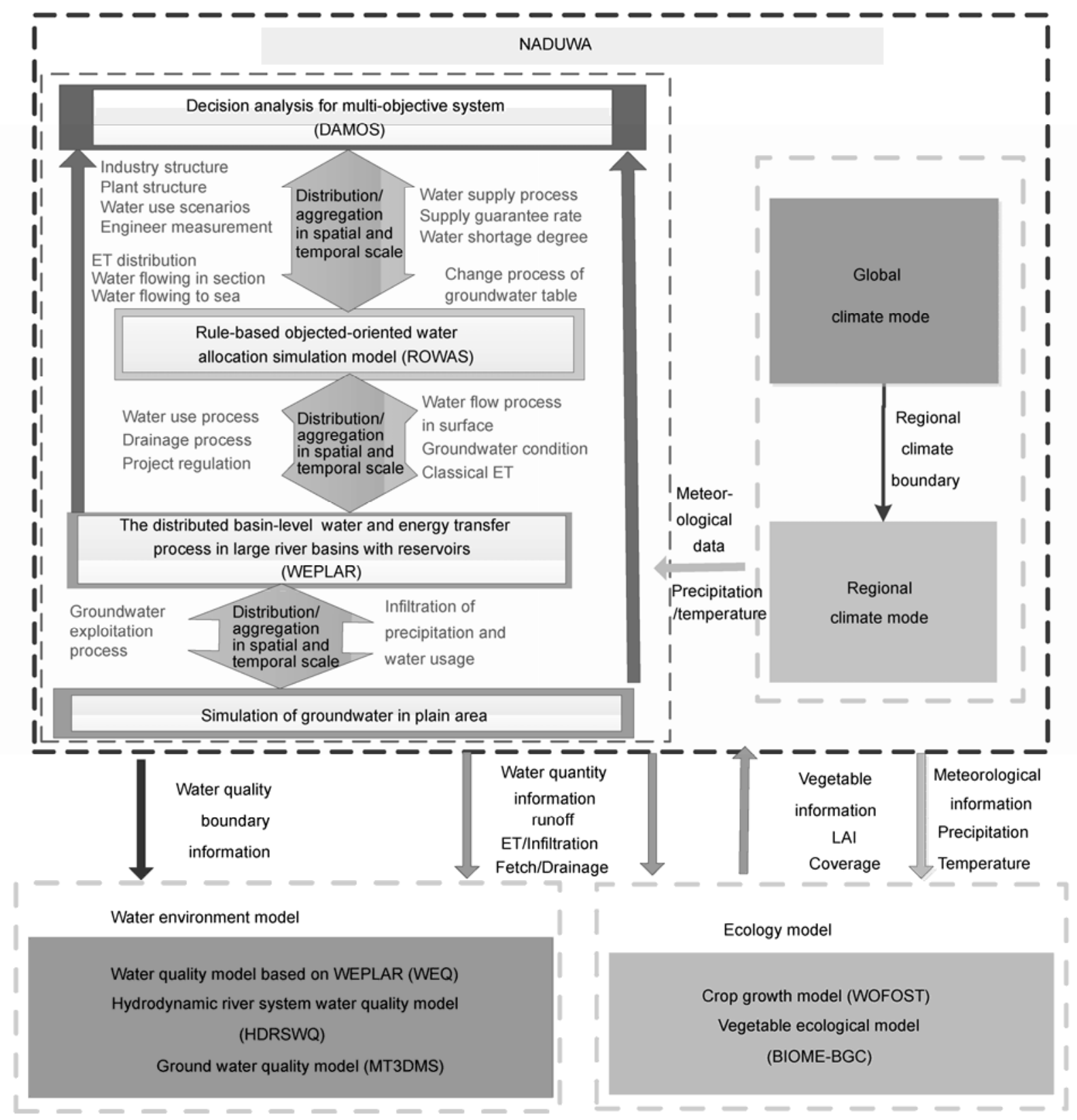

Figure 4 Overall structure of the integrated simulation platform of NADUWA3E for the Haihe River Basin.

water resource allocation model) and WEPLAR model (a model of the distributed basin-level water and energy transfer process in large river basins with reservoirs) was the core model of the integrated simulation platform. The NADUWA model can be further coupled with a water environment model and the basin ecology model ECO to constitute the integrated simulation model of the dualistic water cycle and its associated processes, which is named NADUW3E (natural-artificial dualistic water cycle model with economy, environment and ecology). Meanwhile, to reveal the effects of climate change on the water cycle, a global climate mode is nested within the regional climate mode based on aerodynamic mechanisms to simulate and predict the climate of the Haihe River Basin by coupling with the integrated simulation model. From the coupling relationship between the water cycle mode, water environment model, ecological model and climate model, the simulation platform was established by employing Eclipse RCP technology, component technology, solution technology with a large-scale optimization model and other sophisticated advanced technologies, and by integrating a database and the models to a whole library based on a geographic-information-system platform. The integrated simulation platform could analyze historical evolutionary laws of the basin's water resources, water environment and water ecology and make predictions for various future scenarios. 
The following is a brief description of the NADUWA model, basin water environment model and basin ecological model and the coupling relationship between the latter two models and the NADUWA model.

\subsection{Dualistic water cycle model (NADUWA)}

The dualistic water cycle model (referred to as the NADUWA model) is coupled with the WEPLAR, ROWAS and DAMOS models, which can be used for hierarchical decomposition at macro-, meso- and micro-scales, nested with analog feedback, so as to achieve the integrated simulation of the natural-social dualistic water cycle process. In the NADUWA model, the WEPLAR model is at the bottom and focuses on the micro-scale. The WEPLAR model is mainly used to simulate the coupled movement between the natural and social water cycles for different patterns of water resource allocation. The DAMOS model is at the top and focuses on the macro-scale, where multi-objective integrated decision-making is mainly employed to simulate internal and mutual restriction mechanisms between society, the economy, the environment, water resources and other subsystems, so as to analyze the driving and requirements of water resources for social development. The ROWAS mod$\mathrm{el}$ is in the middle and focuses on the water resource configuration of the social water cycle. The development and validation of the NADUWA model and the coupling relationship among different models have been reported previously [19].

\subsection{Basin water environment model and its coupling with the NADUWA model}

The water environment model for the basin includes a surface water quality model WEQ (a water quality model based on WEPLAR) [20] and groundwater water quality model [21]. The WEQ model has the characteristics of large scale, a complex source of pollution, and intense human activity in the Haihe River Basin. The WEQ model can be used to quantitatively analyze pollutant generation and migration under the condition of wastewater treatment, the water quality in a critical control section, and the compliance of the water function requirement for different patterns of socie-economic development. According to the unit division of the WEPLAR model, the generation of point-source pollution (including industrial and domestic pollution) and non-point source pollution (including pollution from agricultural land, livestock, rural households, soil erosion, and urban runoff), the inflow of such pollution to rivers and their migration and transformation processes in river channels in the WEQ model are closely related to runoff generation, slope runoff routing and channel routing in the hydrological cycle.

The groundwater quality model is a model of the transfer of groundwater nitrogen and phosphorus pollutant solutes that was developed mainly for the Haihe River Plains with serious nitrogen and phosphorus pollution. The computing software PMWIN (Processing Modflow for Windows), which is based on the groundwater flow model and dedicated to the simulation of the migration of groundwater flow and pollutants in porous media, is used as a simulation platform during the modeling. Here, the MODFLOW groundwater flow module and MT3DMS groundwater pollutant migration model are selected as the main modeling tools. Moreover, a first-order irreversible reaction is used for the simulation of the chemical reaction term of solute migration. Detailed simulations are carried out using the Langmuir nonlinear isothermal adsorption model for phosphorus and ammonia nitrogen, while a non-adsorption model is used for nitrate.

Offline coupling is adopted in water-quality models and the hydrological model (Figure 5), thus achieving the migration and transformation of pollutants on the land surface and in rivers and river channels. Further details of the basin water environment model have been previously reported $[20,21]$.

\subsection{Basin ecological model and its coupling with the NADUWA model}

The basin ecological model includes a terrestrial vegetation ecological model and a farmland ecological model, with the latter being a distributed farmland crop-growth model [22] based on the WOFOST crop-growth model, and combined with the WEPLAR model. To overcome the limitation of the WOFOST model $[23,24]$ that it only simulates the entire growth dynamics of annual crops under one set of soil and climatic conditions, the distributed farmland cropgrowth model fully considers the variation in regional climate, soil type and agricultural water drawing, use, consumption and drainage by coupling with the distributed characteristics of the dualistic water cycle in water cycle simulation through the mutual exchange of meteorological data and crop physiological parameters. Thus, after rewriting the main program, meteorological data generation module, crop data generation module and soil data generation module, the main program may circularly calls these rewritten modules and WOFOST module to achieve the distributed simulation of farmland crop growth over a large area.

Combining with the WEPLAR model, the basin terrestrial vegetation ecological model is established based on the BIOME-BGC biogeochemical cycle model [25]. Because the BIOME-BGC model only carries out single-point calculation and simulation, and it is difficult to apply in large-basin simulation, the main program of the original BIOME-BGC model is rewritten and coupled with the WEPLAR model through mutual data exchange. Here the terrestrial vegetation ecological model provides the leaf area index and other ecological indices in different periods and 


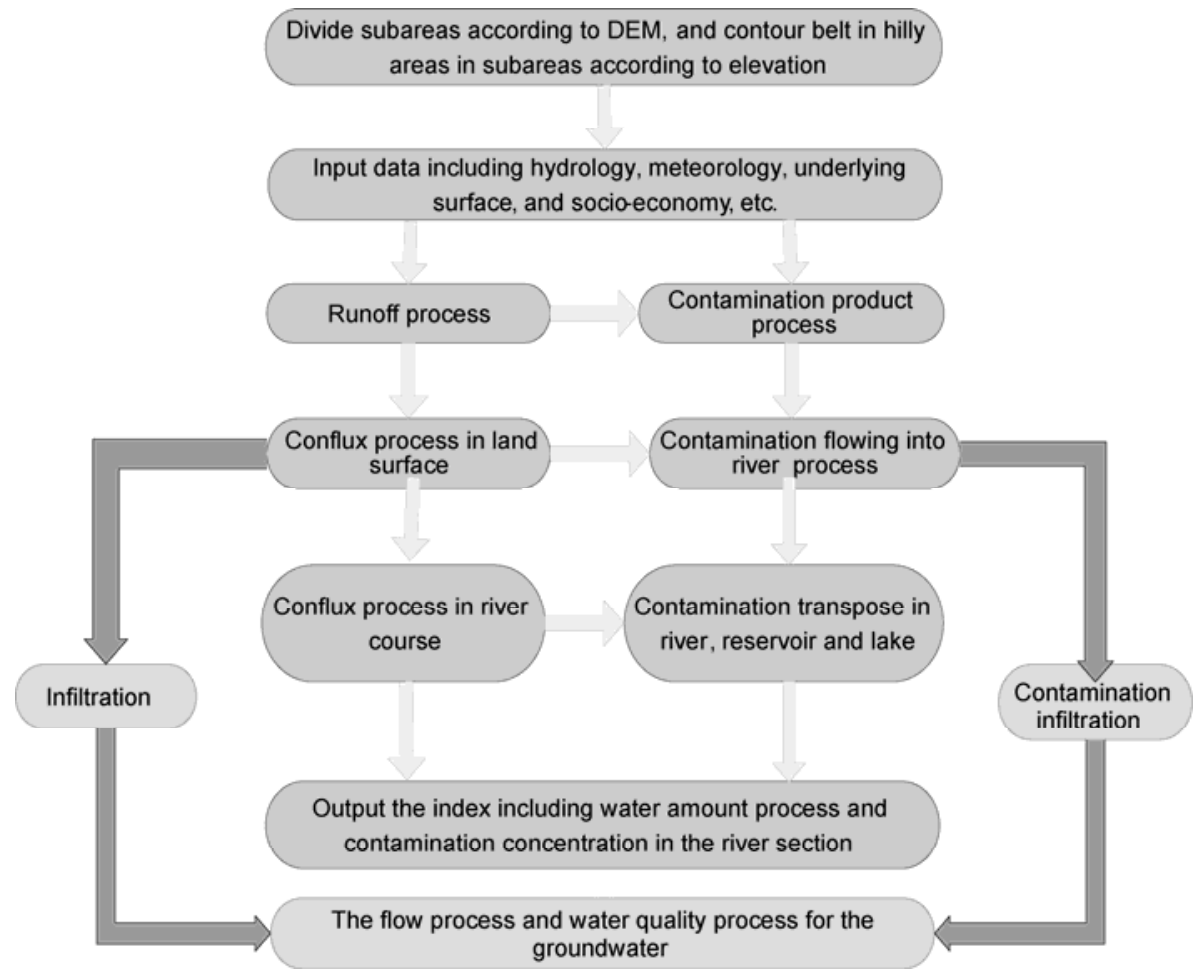

Figure 5 Coupling relationship between the basin water environment model and the water cycle model.

growing seasons for the WEPLAR model, and correspondingly, the WEPLAR model provides data of the temperature, sunlight and other conditions for the basin terrestrial vegetation model. Through the circular calling of meteorology, location, soil, altitude and other data between the above models, the carbon, water and nutrient cycle are simulated in the natural vegetation-soil-atmosphere ecosystem.

Figure 6 shows the coupling relationship between the basin ecological model and WEPLAR model. Further details of the basin ecological model have been given in $[12,26]$.

\subsection{Coupling between the climate mode and water cycle model}

In this study, the regional climate mode RegCM3 (see http://users.ictp.it/ pubregcm/) was used for debugging through the selection of parameterization schemes and the simulation area of the Haihe River Basin, so as to establish a regional climate mode system for the Haihe River Basin. Mutual coupling of the climate mode and water cycle model was achieved through spatial and temporal downscaling. In the spatial dimensions, the commonly used statistical downscaling model was selected for spatial downscaling of the climate mode. In the temporal dimension, Chinese National Weather Generator BCCRCG-WG 3.00 developed by the National Climate Centre in conjunction with the University of Gothenburg, Sweden, was applied to large areas of China. Finally, coupling with the water cycle model was realized through the downscaling of precipitation, tempera- ture and other meteorological elements.

\section{Validation of the integrated simulation model of the dualistic water cycle and its associated processes in the Haihe River Basin}

To achieve the overall modeling of the water cycle and its associated processes, high-sensitivity parameters were selected for parameter calibration and model validation through sensitivity analysis of model system parameters. In this study, the main calibrated parameters were precipitation and temperature as meteorological factors; river runoff, evapotranspiration, reservoir storage variation and groundwater level change as factors of the water cycle; river water quality and groundwater quality as factors of the water environment; and grain yield, leaf area index and net primary productivity (NPP) as factors of the water ecology. The following is a brief description of the calibration results.

\subsection{Validation of the downscaling results for meteoro- logical factors}

In spatial downscaling, climate measurements and climate mode projections for 26 meteorological stations in the basin were selected for parameter calibration and model validation by station, with the calibration period and validation period being 1961-1990 and 1991-2000, respectively. In temporal downscaling, a weather generator was used to 


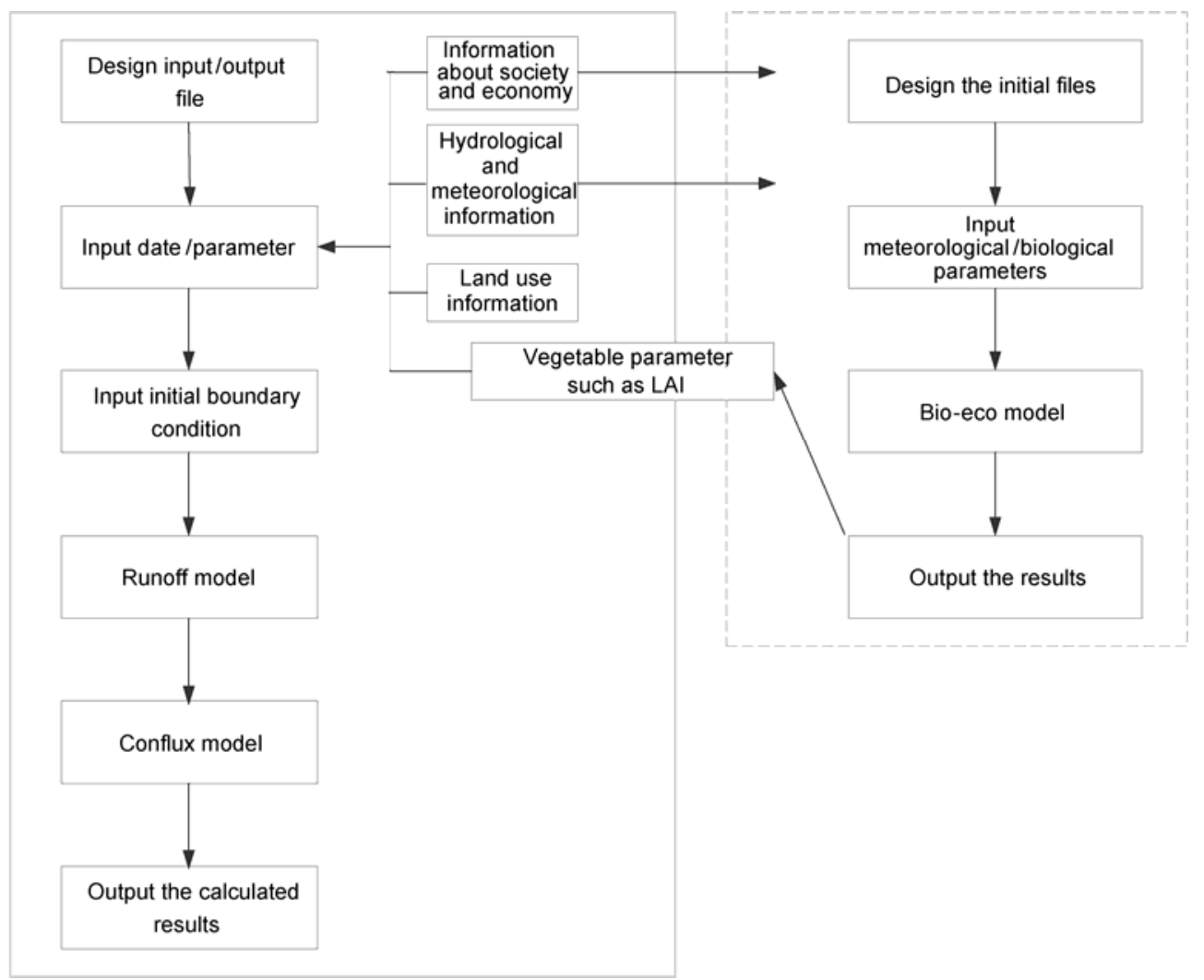

Figure 6 Coupling relationships between the basin water ecological model and water cycle model.

downscale monthly climate data of various stations in the period 2021-2050, and daily data were then obtained to satisfy the requirements of the hydrological model. The results show that the downscaling results of precipitation and temperature was satisfactory for all stations. Figure 7 compares the spatial downscaling results and measurement results for precipitation and temperature at the Beijing Station.

\subsection{Validation of the NADUWA model}

(1) Verification of river runoff. For the purpose of model validation, continuous simulation and calculations were carried out for the 50-year historical hydrological and meteorological series from 1956 to 2005 as well as corresponding underlying surface conditions. The twenty-five years (1956-1979) were taken as the model calibration period, while the remaining years (1980-2005) were taken as the validation period. Taking a typical hydrological station as the validation station, the detailed results of comparison between the calculation results and measurements are presented in Table 1. The table shows that the simulation results were satisfactory for the Haihe River Basin affected by intense human activity, and the Nash efficiency coefficients of simulated and measured runoff exceeded 0.6 at various hydrological stations with a correlation coefficient above 0.8 . Further details of the simulation processes have been
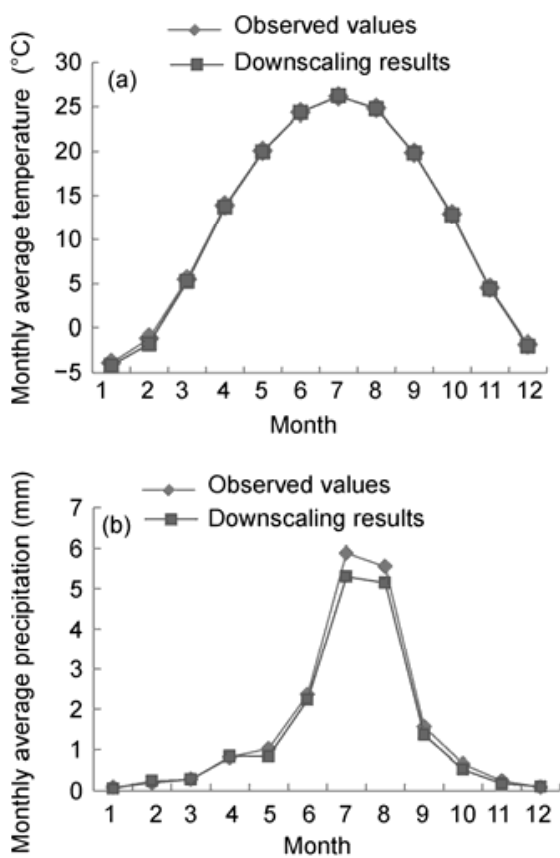

Figure 7 Comparison of downscaling results and measurements of monthly average temperature and precipitation at the Beijing Station (during 1961-2000). (a) Monthly average temperature; (b) monthly average precipitation.

reported previously [19].

(2) Validation of reservoir storage variation. In the cal- 
Table 1 The validation results of runoff in the typical stations

\begin{tabular}{lccccccc}
\hline Station name & Hanjiaying & Chende & Luanxian & Daiying & Miyun reservior & Guantai & Huangbizhuang \\
\hline Relative error (\%) & 0.30 & -5.80 & -1.30 & -4.00 & 11.80 & 3.60 & -5.90 \\
Nash-Sutcliffe efficiency & 0.7 & 0.72 & 0.6 & 0.65 & 0.79 & 0.81 & 0.68 \\
Related coefficient & 0.85 & 0.85 & 0.86 & 0.81 & 0.89 & 0.93 & 0.83 \\
\hline
\end{tabular}

ibration of reservoir storage variation, four large reservoirs, namely Panjiakou, Miyun, Yuecheng and Xidayang, were selected as typical reservoirs in this study, and the simulated and measured storage variations during 1980-2005 were compared. The results show that simulation was basically consistent with measurements, indicating that the model well reflects the operation scheduling of the reservoirs. Further details of the validation have been given in the literature [27].

(3) Validation of the groundwater level. Data used in this study included shallow groundwater-level isopleths of the North China Plain in 1984, 2001 and 2002, deep groundwater-level isopleths in 2001 and 2002, shallow and deep groundwater level isopleths of Hebei in 1975, 1985 and 1992, and groundwater dynamic observation data of groundwater observation wells for 1993-2008. These data were used to validate the groundwater flow field and water levels at 232 observation wells. The measurements were well reproduced by simulation, indicating that the dualistic model had high precision in the simulation of the groundwater flow field. Figure 8 compares the calculated groundwater level and observed water level at all shallow observation wells in 2005.

(4) Validation of evapotranspiration (ET). The years from 2002 to 2005 were taken as the validation period for ET. ET simulated by the model and ET retrieved by remote sensing were compared and found to have a mean difference of $5.5 \%$ in the basin. Figure 9 shows the basic consistency of the evolutionary trends of the simulation results and

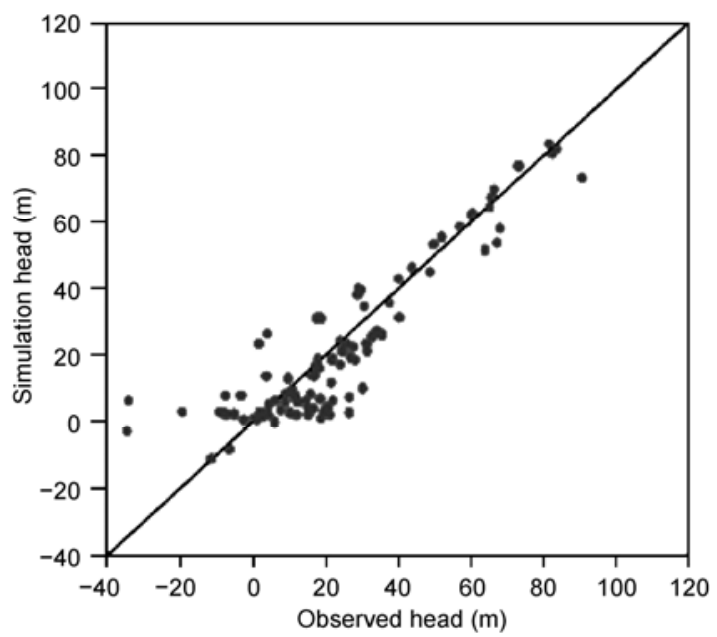

Figure 8 Comparison of the calculated groundwater level and observed water level at all shallow observation wells in 2005 . retrieval results in 2005 .

\subsection{Validation of the water environment}

(1) Validation of the WEQ model. Three indexes were employed to validate the basin water-quality model: the amount of wastewater discharge in the basin, the pollution load, and the critical water quality-control section. In the validation of the amount of waste water discharge in the basin, the wastewater and pollutant discharge from pollution sources of 1270 industrial and mining enterprises in the Haihe River Basin in 2000 were taken as references in this study, these enterprises were specified in the Haihe River Basin Water Resources Assessment [28]. The estimation error was $1.0 \%$ between simulated and evaluated wastewater discharge, indicating that the total amount of the wastewater estimated by the model was basically consistent with the evaluation amount by comprehensive planning in the basin. The indicators Chemical oxygen demand (COD) and $\mathrm{NH}_{3}-\mathrm{N}$ are commonly used in simulation of the pollution load. The values indicate that the simulated concentration is close to the observed value. It was found that the model can describe water quality in the Haihe River Basin, and satisfies the requirements of basin planning, pollution reduction and the total amount control of pollution. Further details of the simulation have been previously reported [20].

(2) Validation of groundwater quality. After roughly estimating the quantity of pollutants in the groundwater system of the Haihe River Plain during various periods, the groundwater quality model of the Haihe River Plain was validated, where the main parameters were the first-order reaction coefficient of each pollutant in groundwater and the dispersion parameter. The interpolation results for various measurement stations in September 2004 were taken as references for model calibration, and the migration and transformation of groundwater pollutants were well described by the model. Figure 10 compares the results for nitrate nitrogen.

\subsection{Validation of the ecological model}

(1) Validation of the distributed farmland crop growth model. The leaf area index and dry matter were validated for winter wheat as the main crop. The validation compared the measurement results and simulation results for the Daxing Experimental Station in 2007-2008. The results show that the simulation of winter wheat growth was very close to 


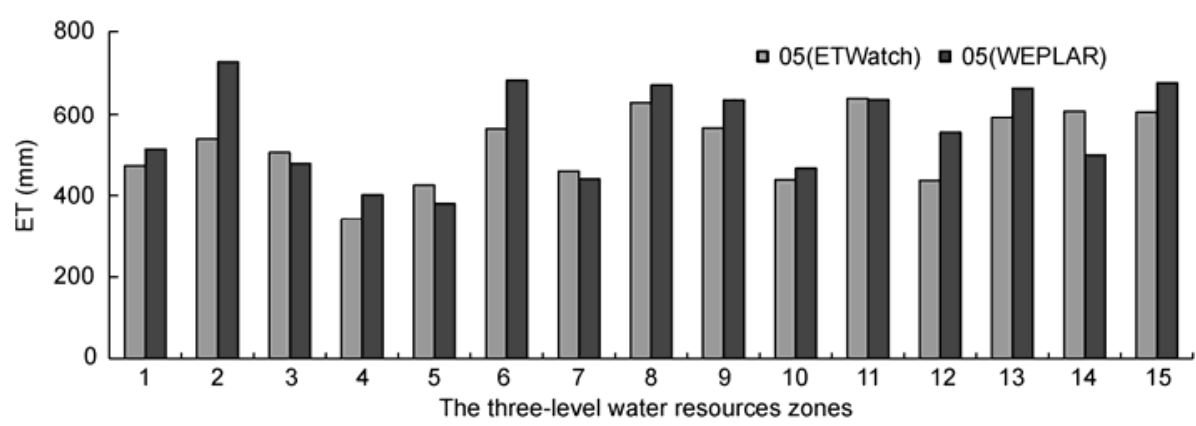

Figure 9 Comparision of ET simulated by the model and ET retrieved by remote sensing in 2005. 1, Luanhe Hilly Area; 2, Luanhe Plain; 3, Beisanhe Hilly Area; 4, Yongdinghe Cetian Dam Upstream; 5, Yongdinghe Cetian Dam to Sanjiadian; 6, Beisihe Downstream Plain; 7, Daqinghe Hilly Area; 8, Daqinghe Dianxi Plain; 9, Daqinghe Diandong Plain; 10, Ziyahe Hilly Area; 11, Ziyahe Plain; 12, Zhangweihe Hilly Area; 13, Zhangweihe Plain; 14, Heilongguang to yundong Plain; 15, Tuhai-Majiahe.
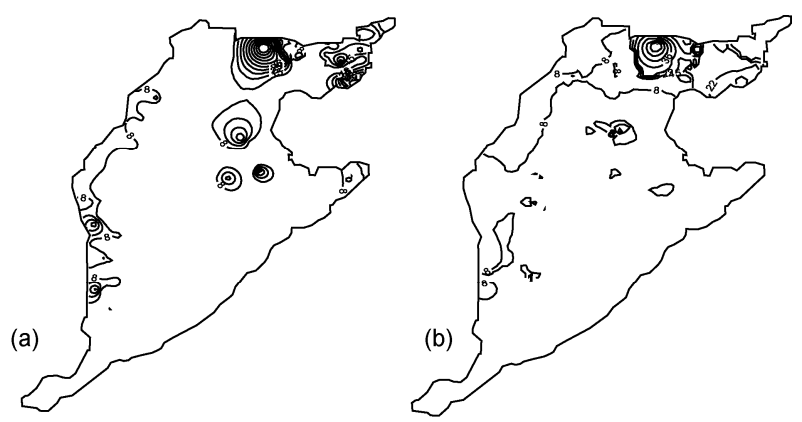

Figure 10 Comparison of the simulation and observation of nitrate nitrogen. (a) Simulation results; (b) observation results.

the measured growth and there was a consistent trend for two different water conditions. Hence, the simulation could well reflect characteristics of crop growth. Further details of validation processes have been previously reported [22].

(2) Validation of the terrestrial vegetation ecological model. The terrestrial vegetation ecological model was validated according to physiological parameters of various kinds of vegetation recommended by the NTSG (Numeric Terra Dynamic Simulation Group) research group. First, experimental observations of Robinia photosynthesis at the Nanxiaohegou Experimental Station and the leaf area index were used to calibrate the physiological parameters of temperate broad-leaved forest; then, simulation results and experimental data of the leaf area index and NPP of temperate broad-leaved forest were validated, respectively. The results show that the terrestrial vegetation model reflects the growth and development characteristics of the natural vegetation. Table 2 lists the validation results for the leaf area index. The NPP validation has been previously reported [26].

\section{Estimation of future evolutionary trends of the water cycle and its associated processes in the Haihe River Basin}

To ensure the future rational use of limited water resources in the Haihe River Basin and to maintain the sound development of the eco-environment, different scenarios were set with comprehensive consideration of the socio-economic, eco-environment and other factors, together with current conditions of basin water resources and the water environment. By employing the integrated simulation platform of the NADUWA3E model, the future evolution of the water cycle and its associated processes in the Haihe River Basin was analyzed under water-control and climate-change conditions. Historical evolutionary laws have been described in [27].

\subsection{Scenarios description}

To enhance the sustainability of water resources, improve the water environment and ecological conditions, and better execute the roles of water resources in the socio-economy and eco-environment of the Haihe River Basin, six boundary conditions were comprehensively considered in a total of 17 scenarios in this study, on the basis of water resources conditions and control measures of future water resources in the Haihe River Basin. Only some scenarios are listed in Table 3 because of space limitations.

Specific boundary conditions were as follows. (1) The target years were 2005 as the benchmark and 2015, 2020 and 2030 as planning years. (2) To fully reflect the abundant

Table 2 The validation results of vegetable LAI from July to September in 2009

\begin{tabular}{|c|c|c|c|c|c|c|c|c|}
\hline Month-day & $7-5$ & $7-11$ & $7-23$ & $8-1$ & $8-11$ & $8-23$ & $9-1$ & $9-11$ \\
\hline Simulated value & 2.16 & 2.22 & 2.33 & 2.410 & 2.49 & 2.62 & 2.70 & 2.780 \\
\hline Measured value & 2.24 & 3.33 & 2.44 & 2.085 & 2.20 & 2.23 & 1.96 & 1.695 \\
\hline
\end{tabular}


and drought water changes in the basin, two hydrological series were selected: a short series of 26 years from 1980 to 2005 (drought water series) and a long series of 50 years from 1956 to 2005 (alternating abundant and drought water series). (3) Groundwater usage [28] was set considering the current groundwater exploitation and exploitation control plan together with the water scale and schedule changes of the South-North Water Diversion Project and the demand for water resources due to economic growth. The current annual mean overexploitation was set as $8 \times 10^{9} \mathrm{~m}^{3}$, that it was planned that the overexploitation would reduce by $1 / 3$ in 2015 and a balance between exploitation and supplementation would be achieved in 2020 and 2030. (4) Three possible goals were set for the amount of water flowing into the sea: $3.5 \times 10^{9} \mathrm{~m}^{3}$ (i.e., the average amount of water flowing into the sea from 1980 to 2005 , reflecting the minimum requirement for total water balance in the basin), $5.5 \times 10^{9}$ $\mathrm{m}^{3}$ (i.e., $1 / 3$ of the average natural river runoff from 1980 to 2005 , reflecting the water balance in the recent period from 1980 to 2005 in the whole basin) and $9.3 \times 10^{9} \mathrm{~m}^{3}$ (i.e., the actual average value from 1956 to 2005 , reflecting the water balance in the long period from 1956 to 2005 in the whole basin). (5) South-North water transfer (including that from the Yangtze River) was based on the planning scheme of the South-North Water Diversion Project with consideration of the water diversion time and water changes. Five possible scenarios were set. For 2005, there is no diversion of water. For 2015 , one scenario was the diversion of $3.65 \times 10^{8} \mathrm{~m}^{3}$ of water by the eastern route and no diversion by the middle route, and a second scenario was the diversion of $2.82 \times 10^{8}$ $\mathrm{m}^{3}$ of water by the middle route and total water diversion of $3.185 \times 10^{9} \mathrm{~m}^{3}$. For $2020,7.29 \times 10^{9} \mathrm{~m}^{3}$ of water is diverted by the eastern and middle routes in stage 1 of the project. For $2030,1.142 \times 10^{10} \mathrm{~m}^{3}$ of water is diverted by the eastern route in stage 2 of the project. (6) The amount of water diverted from the Yellow River was set at $4.62 \times 10^{8} \mathrm{~m}^{3}$ for 2005 (i.e., the average amount from 1980 to 2005), 4.64x $10^{9} \mathrm{~m}^{3}$ for $2015,4.7 \times 10^{9} \mathrm{~m}^{3}$ for 2020 (including $1.06 \times 10^{8}$ $\mathrm{m}^{3}$ of lateral seepage recharge from the Yellow River), and $4.33 \times 10^{9} \mathrm{~m}^{3}$ for 2030 .

\subsection{Estimation of the water-cycle evolution under con- ditions of water control and climate change}

The integrated simulation platform of the NADUWA3W model for the Haihe River Basin was used to run the simulations for the 17 scenarios, and analyses were carried out on the changes in GDP, grain yield, ET, water flowing to the sea, water usage, groundwater overexploitation, and COD under the different water resource conditions. By comparing simulation results and the design goal, optimal scenarios were obtained to ensure sustainable economic and agricultural development and a good ecology and environment condition (see Table 3). Accordingly, the evolution of the water cycle was analyzed for water-control conditions.
Meanwhile, considering climate change, the future trend of water resources from 2020 to 2045 was predicted. Only simulation results for optimal scenarios in a short time series from 1980 to 2005 are listed in the following Tables 4-6.

(1) Estimation of the water cycle evolution under a water-control condition. Table 4 shows that under 19802005 hydrological and water-control conditions, the water consumption, groundwater overexploitation and sea-flowing water have positive trends when the total water usage throughout the basin increases in the current target level year (2005) and the three planning years of 2015, 2020 and 2030.

The available water resources for consumption have an increasing trend, while local water consumption (i.e., excluding water diverted from the Yangtze River and Yellow River) has a decreasing trend. The overexploitation of basin groundwater tends to decrease and basically become zero by 2030 and the groundwater may even recharge; e.g., in S11, the recharge will be about $2.6 \times 10^{8} \mathrm{~m}^{3}$; the amount of water flowing to the sea has an increasing trend, reaching $6.0 \times 10^{9}$ $\mathrm{m}^{3}$ by the planning year 2030 .

In terms of the social lateral water cycle, total water use throughout the basin has an increasing trend, and the amount of water used in the eco-environment will increase more, while the national economic water usage increases more slowly if water-saving measures are taken. In terms of the water supply structure, the level of water diversion has an increasing trend; the local surface water amount is relatively stable, while the groundwater supply decreases. The water usage structure is reflected by reduced agricultural water usage and increased industrial and domestic water usage.

In general, the controls on the total consumption of water resources and water usage structure mentioned above will not only ensure sustainable social and economic development but also reasonably and effectively improve the river water environment and eco-environment of the Bohai Sea and its adjacent coastal areas.

(2) Estimation of water-cycle evolution under climatechange conditions. Maintaining the underlying surface condition for 2020 and considering the above water-usage scenarios, the SRES-A1B mode was used to simulate and analyze the evolutionary trends of the water cycle and water resources in the Haihe River Basin from 2020 to 2045 for trends of future climate change. The results presented in Table 5 show that under the combined driving of factors of climate change (i.e., future basin precipitation and temperature increasing by $10.4 \%$ and $1{ }^{\circ} \mathrm{C}$, respectively) and water resource regulation measures, the overexploitation of basin groundwater can be effectively alleviated by about $80 \%$ in 2020. By 2030, the overexploitation will basically be zero and groundwater is expected to recharge. The amount of the water flowing to the sea has a general increasing trend, and will remain at $7.9 \times 10^{9} \mathrm{~m}^{3}$ or more after 2020 .

Meanwhile, the water resources change accordingly 
Table 3 The setting of water amount scenarios (unit: $10^{8} \mathrm{~m}^{3}$ )

\begin{tabular}{|c|c|c|c|c|c|c|c|c|}
\hline \multirow{2}{*}{$\begin{array}{l}\text { Level } \\
\text { year }\end{array}$} & \multirow[t]{2}{*}{ Scenarios } & \multirow{2}{*}{$\begin{array}{l}\text { Hydrological } \\
\text { series }\end{array}$} & \multirow[t]{2}{*}{ Precipitation } & \multirow{2}{*}{$\begin{array}{l}\text { Over-exploitation } \\
\text { of groundwater }\end{array}$} & \multirow{2}{*}{$\begin{array}{l}\text { Sea-flowing } \\
\text { water }\end{array}$} & \multicolumn{2}{|c|}{$\begin{array}{c}\text { South-North water transfer } \\
\text { (including from Yangtze River) }\end{array}$} & \multirow{2}{*}{$\begin{array}{l}\text { Water transferred } \\
\text { from Yellow River }\end{array}$} \\
\hline & & & & & & Mid-route & East route & \\
\hline 2005 & S1 & \multirow{8}{*}{ 1980-2005 } & 1596.2 & 80 & 35 & 0 & 0 & 46.2 \\
\hline \multirow{2}{*}{2015} & $\mathrm{~S} 2$ & & 1596.2 & 53 & 35 & 0 & 3.65 & 46.4 \\
\hline & $\mathrm{S} 4^{\mathrm{a})}$ & & 1596.2 & 53 & 55 & $56.4 \times 50 \%$ & 3.65 & 46.4 \\
\hline \multirow{3}{*}{2020} & S6 & & 1596.2 & 0 & 55 & 58.7 & 14.20 & 47.0 \\
\hline & $\mathrm{S} 10^{\mathrm{a})}$ & & 1596.2 & 27 & 55 & 58.7 & 14.20 & 47.0 \\
\hline & S16 & & 1596.2 & 55 & 55 & 62.4 & 16.80 & 51.2 \\
\hline \multirow{2}{*}{2030} & $\mathrm{~S} 11^{\mathrm{a})}$ & & 1596.2 & 0 & 93 & 83.9 & 31.30 & 43.3 \\
\hline & S17 & & 1596.2 & 36 & 55 & 86.2 & 31.30 & 51.2 \\
\hline
\end{tabular}

a) The scenarios are relative preference scenarios.

Table 4 The statistics of the dualistic water cycle elements under different scenarios in the Haihe River Basin (unit: $10^{8} \mathrm{~m}^{3}$ )

\begin{tabular}{|c|c|c|c|c|c|c|}
\hline \multirow{2}{*}{ Items } & \multirow{2}{*}{$\begin{array}{c}2005 \\
\text { S1 }\end{array}$} & \multirow{2}{*}{$\begin{array}{c}2015 \\
\mathrm{~S} 4\end{array}$} & \multicolumn{2}{|c|}{2020} & \multicolumn{2}{|c|}{2030} \\
\hline & & & S16 & S10 & S11 & S17 \\
\hline Precipitation & 1596.2 & 1596.2 & 1596.2 & 1596.2 & 1596.2 & 1596.2 \\
\hline $\begin{array}{l}\text { Water transferred from } \\
\text { Yangtze River and Yellow River }\end{array}$ & 41.3 & 74.7 & 134.4 & 117.3 & 157.0 & 166.0 \\
\hline ET (target ET) & 1660.6 & 1667 & 1695.8 & 1675.4 & 1685.2 & 1704.7 \\
\hline Storage variable of groundwater & -66.2 & -54.5 & -20.7 & -18.9 & 2.6 & -5.2 \\
\hline Sea-flowing water & 43.1 & 58.4 & 55.5 & 57 & 65.4 & 62.7 \\
\hline Local surface supply water & 135.6 & 169.5 & 127.4 & 110.0 & 110.4 & 114.7 \\
\hline Groundwater supply & 248.7 & 232 & - & 180.6 & 150.9 & - \\
\hline National economy water use & 381.1 & 386.9 & 448.4 & 399.9 & 410.9 & 456.6 \\
\hline Eco-environment water use & 3.5 & 14.7 & 19.2 & 17.1 & 20.9 & 23.3 \\
\hline Total water use & 384.6 & 401.6 & 467.6 & 417.1 & 431.8 & 479.9 \\
\hline
\end{tabular}

Table 5 The water balance relation under future scenarios in the Haihe River Basin (unit: $10^{8} \mathrm{~m}^{3}$ )

\begin{tabular}{|c|c|c|c|c|c|c|c|}
\hline Items & & & Precipitation & Water transferring & Water into sea & ET & Storage variation \\
\hline \multirow{3}{*}{$\begin{array}{l}\text { Multi-annual average } \\
\text { value from } 2020 \text { to } 2045\end{array}$} & \multirow{2}{*}{2020} & $\mathrm{~S} 16 \mathrm{C}$ & 1752.5 & 134.4 & 79.0 & 1821.2 & -13.3 \\
\hline & & $\mathrm{S} 10 \mathrm{C}$ & 1752.5 & 117.3 & 91.3 & 1785.5 & -7.0 \\
\hline & 2030 & $\mathrm{~S} 17 \mathrm{C}$ & 1752.5 & 166.0 & 88.2 & 1831.2 & -0.1 \\
\hline
\end{tabular}

Table 6 The water resources change under the condition of climate change and water control in the Haihe River Basin in different planning level years (unit: $10^{8} \mathrm{~m}^{3}$ )

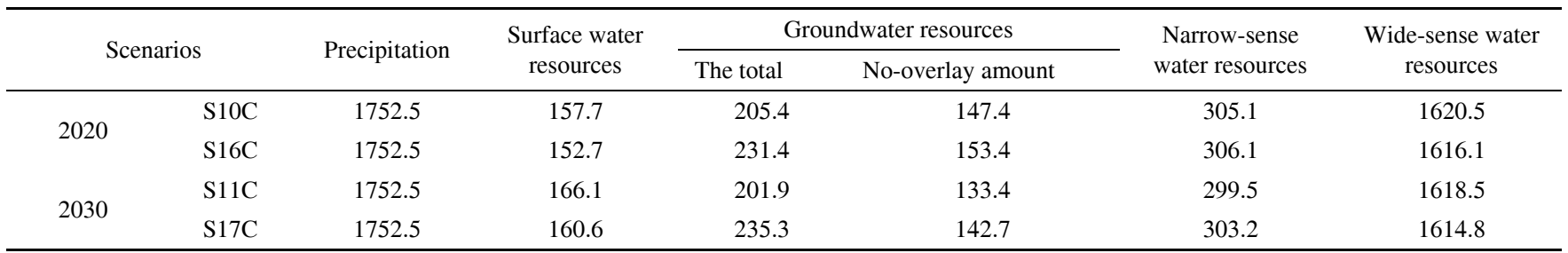

throughout the basin. Compared with the statistical results for the two planning years of 2020 and 2030, the evolution of the water resources amount (see Table 6) has the following trend. With reduction of surface water resources, the groundwater resource increases and the amount of no- overlay groundwater, and there is little change for narrowsense water resources and wide-sense water resources under the conditions of increasing precipitation and an appropriate change in the social water cycle structure and flux (mainly illustrated by greater development and utilization of local 
water resources, greater water diversion and greater agricultural water usage).

\subsection{Estimation of the evolution of the water environ- ment}

Restricted by water-quality objectives in functional areas integrated with the water function adopted in the Ministry of Water Resources and the water environmental function adopted in the Ministry of Environmental Protection, the water quality model in the integrated simulation platform was used to calculate total pollution discharge in S2 in 2015 and S4 and S6 in 2020. The results show that the pollutant-bearing capacities for $\mathrm{COD}$ and $\mathrm{NH}_{3}-\mathrm{N}$ both have overall increasing trends owing to greater south-north water diversion. The pollutant-bearing capacity for COD was 298000, 323000, and 343000 t/a under the water scenarios of S2 in 2015 and S4 and S6 in 2020, respectively. The pollutant-bearing capacity for $\mathrm{NH}_{3}-\mathrm{N}$ was 14500 , 15500 , and $16400 \mathrm{t} / \mathrm{a}$ respectively under the corresponding water conditions.

In addition to the water control scenarios, water pollution will be controlled in the Haihe River Basin according to the tenth and eleventh Five-Year Plans. Different water-quality control scenarios (given in Table 7) were simulated to analyze the pollution load flowing to the sea throughout the basin. The results show that when pollution was reduced by $10 \%$ in 2005, river/sea-entering pollution loads of COD and $\mathrm{NH}_{3}-\mathrm{N}$ reduce accordingly in the basin. In scenario S2E2 without the diversion through the middle route of the South-North Water Diversion Project in the planning year 2015 , the sea-flowing pollution loads of COD and $\mathrm{NH}_{3}-\mathrm{N}$ are 519000 and $75000 \mathrm{t}$ respectively. In scenario S4E2 with water available in the middle route, owing to an increase in the amount of sea-flowing water, sea-entering pollution loads of COD and $\mathrm{NH}_{3}-\mathrm{N}$ increase. In scenario S6E3 in the planning year 2020, owing to the controls of water pollution and water consumption (ET), the amount of water flowing to the sea further increases, and associated sea-entering pollution loads of $\mathrm{COD}$ and $\mathrm{NH}_{3}-\mathrm{N}$ increase significantly compared with those in planning year 2015. The detailed simulation results for various scenarios are listed in Table 8.

\subsection{Estimation of ecological evolution under the effects of nature and human activity}

The distributed farmland crop-growth model was used to stimulate grain yields in the Haihe River Basin under the three scenarios of SRES-A1B, SRES-A2 and SRES-B1 in 2021-2050. Table 9 shows that compared with the historical conditions, the multi-annual average unit yield of winter wheat in the Haihe River Basin is likely to increase by

Table 7 Integrated control list between water quality and water amount

\begin{tabular}{|c|c|c|c|c|}
\hline & 2005 & \multicolumn{2}{|c|}{2015} & 2020 \\
\hline & $\mathrm{S} 1$ & $\mathrm{~S} 2$ & $\mathrm{~S} 4$ & S6 \\
\hline E1: current sewage discharge & S1E1 & & & \\
\hline E2: decreasing by $10 \%$ & S1E2 & S2E2 & S4E2 & \\
\hline E3: decreasing by $20 \%$ & & & & S6E3 \\
\hline
\end{tabular}

Table 8 Water amount and water quality load flowing into the sea and river in the Haihe River Basin

\begin{tabular}{|c|c|c|c|c|c|c|}
\hline Scenarios & $\begin{array}{c}\text { Water into sea } \\
\left(10^{8} \mathrm{~m}^{3}\right)\end{array}$ & Yield $\left(10^{4} \mathrm{t}\right)$ & $\begin{array}{l}\text { River-flowing } \\
\text { amount }\left(10^{4} \mathrm{t}\right)\end{array}$ & $\begin{array}{c}\text { River-flowing } \\
\text { coefficient }\end{array}$ & $\begin{array}{c}\text { Sea-flowing } \\
\text { amount }\left(10^{4} \mathrm{t}\right)\end{array}$ & $\begin{array}{c}\text { Sea-flowing } \\
\text { coefficient }\end{array}$ \\
\hline \multicolumn{7}{|c|}{ COD } \\
\hline S1E1 & 57.6 & 801.7 & 183.3 & 0.229 & 47.6 & 0.260 \\
\hline S1E2 & 57.6 & 801.7 & 168.0 & 0.229 & 43.9 & 0.262 \\
\hline $\mathrm{S} 2 \mathrm{E} 2$ & 64.6 & 812.8 & 175.7 & 0.236 & 51.9 & 0.296 \\
\hline S4E2 & 72.5 & 812.8 & 193.6 & 0.260 & 60.9 & 0.315 \\
\hline S6E3 & 92.3 & 831.1 & 229.2 & 0.332 & 83.0 & 0.362 \\
\hline \multicolumn{7}{|c|}{$\mathrm{NH}_{3}-\mathrm{N}$} \\
\hline S1E1 & 57.6 & 83.6 & 20.4 & 0.244 & 6.7 & 0.328 \\
\hline S1E2 & 57.6 & 83.6 & 18.6 & 0.222 & 6.2 & 0.333 \\
\hline S2E2 & 64.6 & 84.7 & 19.5 & 0.230 & 7.5 & 0.385 \\
\hline S4E2 & 72.5 & 84.7 & 21.3 & 0.251 & 9.0 & 0.425 \\
\hline S6E3 & 92.3 & 86.6 & 25.6 & 0.296 & 12.6 & 0.493 \\
\hline
\end{tabular}

Table 9 Multi-annual average winter wheat yield variable under the climate change scenarios in the Haihe River Basin

\begin{tabular}{lccc}
\hline Items & History & SRES-A1B & SRES-A2 \\
\hline Multi-annual average unit yield $(\mathrm{kg} / \mathrm{ha})$ & 5546.1 & 5938.7 & 5932.2 \\
The rate of change $(\%)$ & & 7.08 & 6.96 \\
\hline
\end{tabular}


about $7 \%$ under the effects of future climate change.

The terrestrial vegetation ecosystem was used to analyze the evolutionary trend of the terrestrial natural vegetation system in the Haihe River Basin in six scenarios (given in Table 10). The different scenarios were designed by combining A1B, A2 and B1 of SRES discharge scenarios proposed by the IPCC with two underlying surface conditions in the current level year 2005 and the planning year 2020. The results in Figure 12 show that in the scenario of future climate change, the NPP of the terrestrial vegetation ecosystem in the Haihe River Basin would increase, but the change rate would differ with a change in the underlying surface. The NPPs of Scenarios 1, 3 and 5 for the current underlying surface condition increased by about $1 \%-2 \%$, and those of scenarios 2, 4 and 6 for the 2020 underlying surface condition increased by about $5 \%-6 \%$.

\section{Discussion and conclusions}

Under the effects of global climate change and intense human activity, water resources shortages, water environmental deterioration and ecological degradation are becoming urgent issues in water resources management of the Haihe River Basin. Owing to the complex relationship among the above three major issues, the water cycle needs to be studied with associated water environment and ecological issues, which is the only way to solve these issues fundamentally. To comprehensively diagnose and solve these issues, an integrated simulation platform of the dualistic water cycle and associated processes (NADUWA3E) for the Haihe River Basin was established by fully analyzing dualistic characteristics of the water cycle evolution in this study.
This paper briefly introduced the integrated simulation platform of the dualistic water cycle and associated processes for the Haihe River Basin. It then simulated and analyzed future evolutionary trends of water resources, ecology and the water environment in the Haihe River Basin by setting different scenarios of water control and climate change. The results provide the foundation for implementing basin water-resource regulation and management based on the whole process of the water cycle. The simulation results are summarized as follows.

(1) In terms of water resources, with greater diversion of water and agricultural water use during the period 2020 -2045 jointly driven by natural factors of climate change (i.e., future basin precipitation and temperature increasing by $10.4 \%$ and $1^{\circ} \mathrm{C}$, respectively) and social factors (i.e., appropriate development and use of local water resources), there is a reduction in surface water, increases in groundwater resources and the amount of non-overlayed groundwater, and little change in either a narrow-sense water resources or wide-sense water resources. At the same time, under the restriction of the amount of water available for consumption in the whole basin and the continuation of the general increasing trend of total water usage, the consumption of water resources, groundwater overexploitation and the amount of water flowing to the sea have increasing trends.

(2) In terms of the water environment, the pollutantbearing capacities for $\mathrm{COD}$ and $\mathrm{NH}_{3}-\mathrm{N}$ have increasing trends in 2015 and 2020 under the restriction of waterquality objectives in the functional areas integrated with the water functional area and water environmental functional area and with south-north water diversion. Meanwhile, the pollution load flowing to rivers and the sea increases with

Table 10 Scenarios setting under the future climate and underlying surface change condition

\begin{tabular}{lcccccc}
\hline Scenarios & Scene 1 & Scene 2 & Scene 3 & Scene 4 & Scene 5 \\
\hline Climate condition & A1B & A1B & A2 & A2 & B1 \\
Underlay condition & Current situation & 2020 & Current situation & 2020 & Current situation & 2020 \\
\hline
\end{tabular}

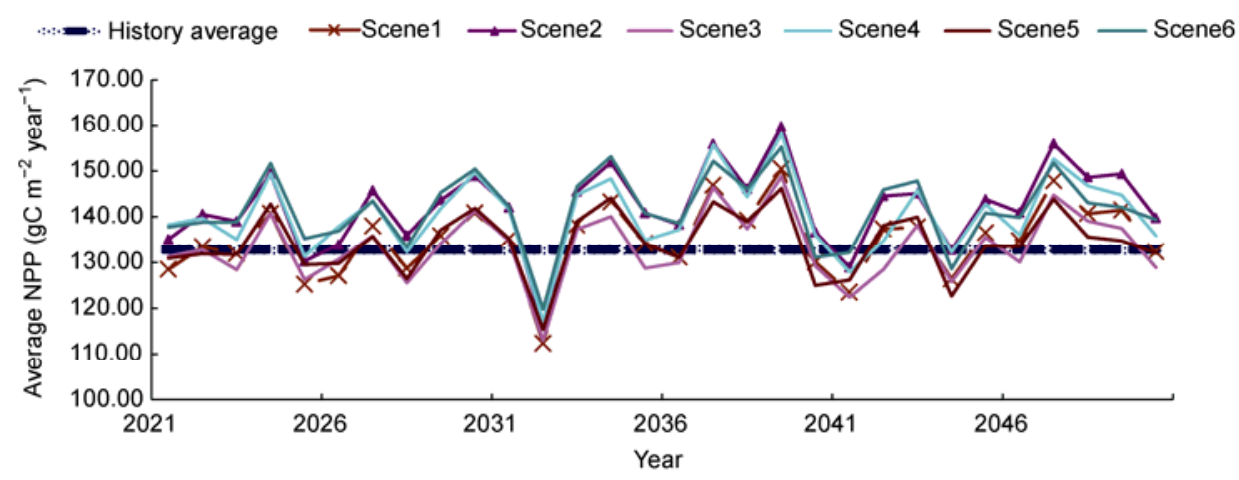

Figure 11 Trend of the change in annual NPP change of territorial vegetation in the Haihe River Basin in scenarios of climate change and underlying surface change from 2021 to 2050. 
an increasing flow of water to the sea.

(3) In terms of ecology, the winter wheat mean unit yield increases by about 7\% and the NPP in the natural ecosystem has an increasing trend in the Haihe River Basin in the scenarios SRES-A1B, SRES-A2 and SRES-B1.

It should be noted that the coupling mechanism between the natural-social dualistic water cycle and its associated processes is complex, and relevant studies are still in an exploratory stage and there is a need for further research. A corresponding quantitative tool—a coupling simulation platform for the dualistic water cycle and its associated processes in the Haihe River Basin should also be further developed.

The authors express their sincere gratitude to all who provided help in the study. This work was supported by the National Basic Research Program of China (2006CB403404), the Innovation Foundation Program of the National Natural Science Foundation of China (51021066), the Key Program of the National Natural Science Foundation of China (50939006), National Water Pollution Control and Management Technology Major Projects (2008ZX07209-009-4), the National Key Technology and R\&D Program (2010BAC69B02) and the National Natural Science Foundation of China (51109224).

1 Yu P S, Yang T C, Wu C K. Impact of climate on water resources in southen Taiwan. J Hydro, 2002, 260: 161-175

2 Zhang $\mathrm{J}$ Y. The evaluation of threshold and integrated effect for climate change impacting on water resources in China (in Chinese). Technical Report, The Center of Water Information, MWR, 2005

3 James D F, Barry S, Johanna W, et al. Climate change in the Arctic: Current and future vulnerability in two Inuit communities in Canada. Geogr J, 2008, 174: 45-62

4 Trenberth K E. Conceptual framework for changes of extremes of the hydrological cycle with climate change. Climatic Change, 1999, 42: 327-339

5 Chen Y N, Xu Z X. Plausible impact of global climate change on water resources in the Tarim River Basin. Sci China Ser D: Earth Sci, 2005, 48: 65-73

6 Ali U K, Ayhan E, Sukriye O. Possible impacts of climate change on soil moisture availability in the Southeast Anatolia Development Project Region (GAP): An analysis from an agricultural drought perspective. Climatic Change, 1998, 40: 3-4

7 Woodhouse C A, Overpeck J T. 2000 Years of drought variability in the central United States. Bull Amer Meteorol Soc, 1998, 79: 26932714

8 Wang Z W, Tang H Y, Zhang H T. Analysis of changing flood characteristic in south china during the recent 50 years. J Trop Meteorol, 2005, 11: 206-212

9 Arnold J G, Fohrer N. Swat 2000: Current capabilities and research opportunities in applied watershed modeling. Hydro Process, 2005, 19: 563-572

10 Singh V P. Computer Models of Watershed Hydrology. Highlands Ranch, Colorado: Water Resource Publisher, 1995
11 David Y, Jack S, David R. et al. WEAP21-A demand-, priority-, and preference-driven water planning model: Part 1, model characteristics. Water Int, 2005, 30: 487-500

12 Liu J H, Qin D Y, Wang H, et al. Dualistic water cycle partners and its evolution in Haihe River basin. Chin Sci Bull, 2010, 55: 512-521

$13 \mathrm{Yu} \mathrm{W} \mathrm{D.} \mathrm{Water} \mathrm{balance} \mathrm{and} \mathrm{water} \mathrm{resources} \mathrm{sustainable} \mathrm{development}$ in Haihe River Basin (in Chinese). J China Hyd, 2008, 28: 79-82

14 Han P, Zhou Y J. Water resources comprehensive management in Haihe River Basin (in Chinese). Haihe Water Resources, 2008, 5: 4-7

15 Wang Z M. Target and countermeasures of water ecological environment recovery in the Haihe river basin (in Chinese). China Water Resources, 2002, 4: 12-13,71

16 Haihe water conservancy commission (HRCC). The water quality in Haihe River Basin (2005 annual report) (in Chinese). Tianjin: Water Resources Protection Bureau of Haihe River Basin, 2005

17 Xie L B. Bohai Sea: The third pole in China economy grows (in Chinese). The Economic Observer Paper, Oct.4, 2009

18 The People's Republic of China. China Water Resources Bulletin 2008 (in Chinese). Beijing: China Water Resources \& Hydropower Press, 2008

19 Jia Y W, Wang H, Zhou Z H, et al. Development and application of dualistic water cycle model in Haihe River Basin: I. Model development and validation (in Chinese). Advance in Water Science, 2010, 21: $1-8$

20 Niu C W, Jia Y W, Wang H, et al. Assessment of water quality under changing climate conditions in the Haihe River Basin, China. In: Norman E P, Valentina Krysanova, Ahti Lepistö, et al., eds. Proceedings of symposium H014 held during IUGG2011 in Melbourne, Australia, July, 2011. IAHS Publ. 345, 2011, 165-171

21 Liu J, Zheng C, Zheng L, et al. Ground water sustainability: Methodology and application to the North China Plain. Ground Water, 2008, 46: 897-909

22 Jia Y W, Shen S H, Niu C W, et al. Coupling crop growth and hydrologic models to predict crop yield with spatial analysis technologies. J App Remote Sens, 2011, 5: 053537

23 Van Keulen H, Wolf J. Modeling of agricultural production: Weather, soil and crops. Wageningen: Simulation Monographs, Centre for Agriculture Publishing and Documentations Simulation Monographs, 1986

24 Hijmans R J, Guiking I M, van Diepen C A. User guide for the WOFOST 6.0 crop growth simulation model. Technical document 12, DLO Winand Staing Centre, Wageningen, the Netherlands, 1994, 143-146

25 Running S W, Hunt R E. Generalization of A Forest Ecosystem Process Model for Other Biomes, BIOME-BGC, and An Application for Global—Scale Models. San Diego: Academic Press, 1993

26 Peng H, Jia Y W, Qiu Y Q, et al. Eco-hydrological simulation and prediction in the Haihe River Basin by coupling BIOME-BGC model with WEP-L Model. In: Norman E P, Valentina Krysanova, Ahti Lepistö, et al., eds. Proceedings of symposium H01 held during IUGG2011 in Melbourne, Australia, July, 2011. IAHS Publ. 345, 2011, 177-182

27 Jia Y W, Wang H. Integrated Simulation of Water Cycle and Its Associated Processes in the Haihe River Basin (in Chinese). Beijing: Science Press, 2012

28 Ren X S. Water Resources Assessment of the Haihe River Basin. Beijing (in Chinese). Beijing: China Water Resources \& Hydropower Press, 2007. 329-339

Open Access This article is distributed under the terms of the Creative Commons Attribution License which permits any use, distribution, and reproduction in any medium, provided the original author(s) and source are credited. 